\title{
Psychotropic medication use for paediatric mental health patients in an Emergency Department.
}

Sinead M O'Donnell MD 1,3

Anna Carison NP 1

Ashley Hill 3

Daniela Say MB 1

Harriet Hiscock 2,4,5

Franz E Babl MD 1-3

1 Emergency Department Royal Children's Hospital, Parkville, Australia

2 Department of Paediatrics, University of Melbourne, Melbourne, Australia

3 Emergency Research, Murdoch Children's Research Institute, Parkville, Australia

4 Health Services Research Unit, Royal Children's Hospital, Melbourne, Victoria, Australia

5 Centre for Community Child Health, Murdoch Children's Research Institute, Melbourne, Victoria, Australia

\section{Correspondence to:}

Dr Sinéad O'Donnell

Emergency Department

The Royal Children's Hospital

50 Flemington Road

Parkville, Victoria 3052 Australia

Short Title: Medication use in paediatric mental health.

\section{Funding}

H Hiscock is supported by a National Health and Medical Research Council (NHMRC) Practitioner Fellowship (1136222).

The MCRI is supported by the Victorian Government's Operational Infrastructure Support Program.

FEB's time was part funded by a grant from the Royal Children's Hospital

Foundation, Melbourne, Australia and an NHMRC Practitioner Fellowship.

\section{Financial disclosure}

Nil

\section{Conflicts of interest:}

None

This is the author manuscript accepted for publication and has undergone full peer review but has not been through the copyediting, typesetting, pagination and proofreading process, which may lead to differences between this version and the Version of Record. Please cite this article as doi: $10.1111 / 1742-6723.13617$

This article is protected by copyright. All rights reserved. 
Data Availability Statement:

No additional data are available to be shared

\section{Abbreviations}

ABD acute behavioural disturbance

ED emergency department

EMR Electronic Medical Record

ICD International Statistical Classification of Diseases and Related Health Problems IM intramuscular

$\mathrm{MH}$ mental health

PO per oral

SI suicidal ideation.

\section{Word count:}

Abstract: 250

Body of manuscript: 2600

This article is protected by copyright. All rights reserved. 


\section{Table of contents summary}

Paediatric mental health presentations to emergency departments are increasing yet there is a paucity of evidence to inform choice of psychotropic medication regimens in this population.

What is already known

- Mental health presentations to the emergency department are increasing in children and adolescents.

- There is a paucity of research into what medications are used; and for which children and adolescents.

- Chemical restraint in children in the ED is currently not evidence based.

\section{What this study adds}

- Relatively few children and adolescents with mental health presentations receive psychotropic medications in ED.

- Medicated children with mental health presentations in the ED are more likely to be male, have a more acute triage category (ATS 1 or 2), have an ED LOS greater than 12 hours and present after hours.

- Most children who received psychotropic medication in the ED had a diagnosis of acute behavioural disturbance or suicidal ideation.

This article is protected by copyright. All rights reserved. 


\section{Contributor's statement page}

SOD and AC conceived the study, extracted and analysed the data, wrote the first draft of the paper and revised all drafts. AH and DS assisted with data entry, review of data and revision of the drafts of the paper.

FEB and $\mathrm{HH}$ assisted with the design of the study protocol, obtained ethics approval and revised the drafts of the paper.

All authors approved the final draft for submission.

This article is protected by copyright. All rights reserved. 


\section{ABSTRACT}

\section{Objectives:}

There is paucity of evidence for psychotropic medication use in children and adolescents presenting with mental health $(\mathrm{MH})$ problems to the emergency department (ED). We set out to describe paediatric psychotropic medication use in the ED.

\section{Methods:}

We conducted a retrospective electronic medical record review of ED patients with $\mathrm{MH}$ discharge codes at a tertiary paediatric ED in 2018. We assessed the epidemiology and management of patients who received a psychotropic medication. We calculated the odds ratios (ORs with 95\% confidence intervals (CI)) of key demographic factors of medicated vs non-medicated $\mathrm{MH}$ patients.

\section{Results:}

During 2018 there were $1695 \mathrm{MH}$-related presentations to the ED. Of these, 280 presentations resulted in the patient receiving a psychotropic medication (16.5\%). Medicated children with $\mathrm{MH}$ illness were more likely to be male (OR 1.50, $\mathrm{Cl} 1.16$ 1.96), have a more acute triage category (OR 3.37, $\mathrm{Cl} 2.28-4.98)$, have an ED LOS greater than 12 hours (OR 3.96, $\mathrm{Cl} 2.56-6.13$ ) and present after hours (OR $1.51 \mathrm{Cl}$ $1.16-1.96)$. Most had a diagnosis of acute behavioural disturbance or suicidal ideation. A variety of treatment regimens were used but children primarily received a single oral agent (diazepam or olanzapine). Parenteral medications were given in $8.6 \%$. No adverse events were recorded.

\section{Conclusion:}

A minority of children with $\mathrm{MH}$ presentations to the ED were medicated. It will require multicentre research to determine the most effective and safe acute psychotropic agents for oral and parenteral use in children in the ED.

This article is protected by copyright. All rights reserved. 


\section{Key words:}

\section{Paediatrics}

\section{Emergency department}

Mental health

Psychotropic medication

Acute behavioural disturbance

This article is protected by copyright. All rights reserved. 


\section{INTRODUCTION}

The paediatric emergency department (ED) plays an important role in the assessment and management of children and adolescents in $\mathrm{MH}$ crises. In recent years Australian ED paediatric mental health $(\mathrm{MH})$ presentations have increased significantly ${ }^{1}$ compared to paediatric presentations ${ }^{2}$ and adult $\mathrm{MH}$ presentations ${ }^{1,3}$. $\mathrm{MH}$ emergencies are becoming an increasing part of Australian paediatric ED practice with patients more likely to arrive out of business hours, be triaged as urgent, have prolonged stays and require an acute admission ${ }^{1,2,4}$. Similar findings have been reported in the USA ${ }^{5,6}$.

International consensus supports patient advocacy, increasing community services, improving staff education and training ${ }^{7}$, minimising the use of restrictive intervention and improving de-escalation ${ }^{8,9}$ in $\mathrm{MH}$ emergencies. However, when these strategies fail, medication use in ED may be necessary to ensure a child or healthcare worker's safety or to expedite the patient's medical evaluation. Multiple high quality studies comparing different agents for the management and treatment of aggression and violence in adults in the ED setting have been published ${ }^{10,11}$. We know that children and adolescents are receiving psychotropic medications in EDs in Australia ${ }^{12,13}$ however, there is little information in the literature about the use of chemical restraint in this population and guidance remains unclear as multiple different drugs, doses and administrative methods have

This article is protected by copyright. All rights reserved. 
been used in various studies ${ }^{14,15,16,17}$. The National Institute for Care and Excellence $(\mathrm{NICE})^{9}$ and the American Psychiatric Association (APA $)^{18}$ provide guidance on psychotropic medication use in children but the background evidence and support for this guidance is very limited. The most recent consensus statement from the American Association for Emergency Physicians ${ }^{19}$ favours a multimodal approach to managing aggression and agitation in the paediatric ED. It provides guidance on treatment regimens for use in different clinical situations, although limited evidence exists for first-line agents. It is therefore not surprising that there is marked variation internationally in the prescribing practice of anxiolytics, stimulants, antidepressants and antipsychotics for children and adolescents in the $E D^{20}$.

Baker et $\mathrm{al}^{21}$ concluded that there was no evidenced based medication regimen available to effectively treat agitated children with $\mathrm{MH}$ disorders. One small double-blind placebo-controlled study studied 21 boys and showed no difference between medication (diphenhydramine) and placebo in the management of acute behavioural disturbance $(A B D)^{22}$.

The safety profile of psychotropic medications when used in the acute management of $A B D$ and agitation in the ED paediatric population has not been well described or studied. Kendrick et al reported adverse events in $<5 \%$ of their paediatric cohort who received antipsychotics in the ED for treatment of 
aggression or agitation ${ }^{23}$. Droperidol use has been reported to be safe and effective in both the pre-hospital and ED settings for ABD in adolescents ${ }^{24,25}$. It is difficult to ascertain true adverse event profiles in the literature for psychotropic medications as sedation/somnolence, often considered to be an adverse event, is usually the desired effect for their use in the ED population.

Before embarking on interventional medication trials in children it is important to understand what psychotropic medications are used in children in the ED and what $\mathrm{MH}$ presentations require their use. We aimed to describe $\mathrm{MH}$ patients who received a psychotropic medication in a paediatric ED and how they differ from other $\mathrm{MH}$ patients.

\section{METHODS}

\section{Design and Setting}

We conducted a retrospective electronic medical record (EMR) review of all psychotropic medication use in ED patients with $\mathrm{MH}$ discharge codes who presented to the Royal Children's Hospital (RCH) in Melbourne, Australia between January 1st and December $31^{\text {st }} 2018 . \mathrm{RCH}$ is a tertiary children's hospital with an annual ED census of 85,347 children in 2018 . It is a designated mental health facility under Victorian Mental Health Act regulation ${ }^{26}$. The $\mathrm{MH}$ services consist of the ED with an

This article is protected by copyright. All rights reserved. 
in-house and on call MH team, a 16-bed adolescent inpatient unit and outpatient services. Although the hospital MH team is available for consult, they are usually not involved in the choice of acute medication for ED patients. The Human Research and Ethics Committee (HREC) at RCH approved the study (HREC QA/51710/RCHM-2019).

\section{Study procedure}

Sixty-six MH related International Classification of Diseases, Revision 10, Australian Modification (ICD-10-AM) diagnostic codes were used to identify all $\mathrm{MH}$ presentations to the RCH ED (see Appendix 1). This list included all MH diagnoses available for treating staff to use and other diagnoses not specifically $\mathrm{MH}$ related but often associated with $\mathrm{MH}$ presentations, such as ingested foreign body, hallucinations and forearm laceration. EMRs of all identified MH presentations were manually assessed to confirm $\mathrm{MH}$ related presentations, exclude non- $\mathrm{MH}$ presentations, and assess the ED and $\mathrm{MH}$ clinician diagnoses and any underlying $\mathrm{MH}$ diagnoses reported in the medical record.

Inclusion criteria:

- All presentations aged 7 to $<\mathbf{1 8}$ years of age presenting to ED, who had a $\mathrm{MH}$ diagnosis assigned by the ED and / or MH clinician.

\section{Exclusion criteria:}

This article is protected by copyright. All rights reserved. 
- Children under 7 and $\geq 18$ years of age

- Presentations with a diagnosis of ingested foreign body or forearm laceration, where there was no $\mathrm{MH}$ issue.

\section{Definitions:}

To be sectioned under Section 351 of the Victorian Mental Health Act is the apprehension of a person by police if the person appears to have a mental illness and needs to be apprehended to prevent harm to the person or another person, and subsequent transport to a medical or $\mathrm{MH}$ practitioner for examination ${ }^{26}$. ED triage urgency was defined using the national Australian triage scale (ATS) ${ }^{27}$.

For identified patients, we extracted relevant demographic, diagnostic, management and follow up data, using an a priori developed coding dictionary. Data extractors were trained and intermittently audited ${ }^{28}$.

\section{Analysis}

Data were entered into an Excel database (Excel, Microsoft, Seattle, WA, USA) and analysed using Stata 14 (Stata Corp, College Station, Tx, USA). We reported demographic data for all $\mathrm{MH}$ presentations using frequencies and percentages with 95\% confidence intervals ( $\mathrm{Cls})$, and additional presentation related variables for the subset of presentations that received medications. Our primary analysis was focused

This article is protected by copyright. All rights reserved. 
on identifying the differences between patients who received medications and those who did not using odds ratios (ORs) and 95\% confidence intervals ( $\mathrm{Cl}$ ) of key demographic factors.

\section{RESULTS}

In 2018 there were 85,347 presentations to RCH ED and 25,095 presentations in children aged 7-17 years. Of these 25,095 presentations, 1695 had a $\mathrm{MH}$ diagnosis representing $6.8 \%$ of all ED presentations in the $7-17$ years age group. In 280 (16.5\%) of these presentations, patients received treatment with a psychotropic medication. Three hundred and eighty-eight medication administrations were given across 280 patient presentations and no adverse effects were documented. Patients who received psychotropic medications in the ED differed from $\mathrm{MH}$ patients who did not receive medications. Table 1 details the demographic information of the total $\mathrm{MH}$ cohort and the subset of patients who did and did not receive psychotropic medication management. Those who received medications were more likely to be male (OR 1.50, $\mathrm{Cl} 1.16-1.96$ ), have a more urgent triage category (ATS 1 or 2) (OR 3.37, $\mathrm{Cl} 2.28$ - 4.98), have an ED LOS greater than 12 hours (OR 3.96, Cl 2.56-6.13) and present after hours between 17.00pm and 07.59am (OR $1.51 \mathrm{Cl} 1.16-1.96$ ). There were no significant differences in age, day of presentation or admission rates between the medicated and non-medicated cohorts. Table 2 displays other important demographic variables. Over half of these patients arrived by ambulance

This article is protected by copyright. All rights reserved. 
or police escort (52.5\%, OR 1.97, $\mathrm{Cl} 1.52-2.56)$ and $21.1 \%$ were sectioned on arrival (OR 1.93, $\mathrm{Cl}$ 1.39-2.68). Children who received medications were also more likely to be under DHHS guardianship (OR 1.87, $\mathrm{Cl} 1.28$ - 2.73). The majority (85.7\%) had prior engagement with psychiatry or community care services and $90.7 \%$ had a past psychiatric diagnosis. There was no statistically significant association between admission and requiring any medication (OR 1.16, $\mathrm{Cl}$ 0.87-1.55) compared to presentations with no medication and no statistically significant association between admission in patients receiving IM medication (OR 2.10, $\mathrm{Cl}$ 0.89-4.95) compared to PO only.

Most patients $(76.1 \%, 213 / 280)$ received only one medication during their ED presentation. Forty patients (14.3\%) received two medications, 15 patients (5.4\%) received three medications and 12 patients (4.3\%) received four or more medications (see Table 3). There was a range of 1-8 medication administrations per presentation. In 256 patient presentations (91.4\%), only an oral medication was given ( $n=348,89.7 \%$ of total meds administered). IM medications were given in 24 patient presentations ( $8.6 \%)$, ( $n=40,10.3 \%$ of total meds administered). An oral medication was given first line in 262 cases (93.6\%) and IM was given first line in 18 cases (6.4\%). The most common orally administered medication was diazepam followed by olanzapine and lorazepam. The most frequently given IM medication was droperidol followed by olanzapine and midazolam. Table 4 describes the type of

This article is protected by copyright. All rights reserved. 
medication administered, order of administration and median dose used. When oral medication was given as a first-line agent, 53 of these patients went on to need a second medication. Only 4 of these $53(7.5 \%)$ patients were escalated to an IM medication as a second medication. The requirement for an IM medication increased with next dose $\left(1^{\text {st }}\right.$ dose IM 6.4\%, $2^{\text {nd }}$ dose IM $17.2 \%$ and $3^{\text {rd }}$ dose IM $17.4 \%)$.

Table 5 lists the most likely diagnoses given to the medicated cohort by ED and MH practitioners. $\mathrm{ABD}$ and suicidal ideation (SI) were the most commonly attributed diagnoses, accounting for $40.7 \%$ and $29.4 \%$ of all medications administered, respectively. For both groups most patients required a single orally administered medication while in the ED (Table 3). More IM medications were prescribed for the ABD patient cohort than the SI cohort (23 vs. 5 medications, respectively, OR 2.96, Cl 2.22-3.94).

Code grey response.

A Code Grey is a coordinated staff response to an agitated or aggressive patient. Encounters requiring medications were 9.2 times more likely to be associated with a Code Grey than non-medicated encounters. (95\% Cl 6.38-13.25). A total of 53 Code Grey responses resulted in the administration of psychotropic medications. Just over $17 \%$ of total medications given were during a Code Grey event. Oral

This article is protected by copyright. All rights reserved. 
medication was dispensed in 31 presentations and IM medication in 22 presentations. A total of 79 individual medication doses were dispensed and $30 \%$ of patients required a $2^{\text {nd }}$ medication during their Code Grey event. This $2^{\text {nd }}$ medication was more likely to be administered via the IM route (62.5\% versus $37.5 \%)$. The most frequently oral and IM administered medications during a Code Grey event were olanzapine PO and IM droperidol respectively.

\section{DISCUSSION}

We have described an important population of paediatric patients presenting to the ED at a tertiary centre who were administered psychotropic medications. A minority of children with $\mathrm{MH}$ diagnoses receive psychotropic treatment during their ED visit (16.5\% of all $\mathrm{MH}$ patients presenting). This is higher than other reports ${ }^{17}$. Medicated children in our ED are more likely to present after hours, have a higher triage category (ATS 1 or 2 ) and have a LOS $>12$ hours. If a child presented with a diagnosis of $A B D$ they were more likely to receive a psychotropic medication during their stay than if they had other presenting diagnoses.

A child is more likely to receive an oral medication in the first instance. There is a low oral to IM medication conversion rate (2.3\%). We found that if IM medications are required, they were primarily given as a first $(45 \%)$ or second (27.5\%) medication although some changed to IM medication administration after further oral

This article is protected by copyright. All rights reserved. 
medication doses had failed. Two thirds of presentations requiring IM medications were diagnosed with $A B D$.

Children who received medications were not admitted more. However admission was associated with multiple medication (>=2) administrations (OR 2.54, $\mathrm{Cl}$ 1.414.54) compared to single administration only. Due to the broad range of medications used, reasons for medication use and broad range of diagnoses, no association is seen between admission and medication use alone. However, when multiple medications are administered, patients are $\mathbf{2 . 5}$ times more likely to be admitted.

A wide range of medication regimens was used to chemically restrain children and adolescents with $A B D$, violence or aggression however, there was very little variation in our prescriptions as shown in Supplemental Table 1. The most commonly administered medications do not differ greatly from a report of aggressive children in another Australian paediatric centre ${ }^{13}$. Olanzapine, which was commonly administered in our ED, has been shown to be efficacious in an adult randomised controlled trial $(\mathrm{RCT})^{11}$. Khan et al retrospectively examined IM olanzapine and IM ziprasidone in the management of acute agitation and aggression in children and adolescents $^{14}$. They found no difference in efficacy or safety profile. To date, there is no high level evidence studying the best psychotropic management of $A B D$ and violence in the paediatric ED environment ${ }^{8}$. An adequately powered multicentre $\mathrm{RCT}$, comparing such medications, is required specifically for this population where

This article is protected by copyright. All rights reserved. 
outcomes of success of sedation, adverse events etc. are assessed to provide evidence for their optimal use and guidance for clinicians.

Though limited by the retrospective methodology of our study, we did not identify any adverse effects of medication administration (including respiratory depression, extrapyramidal reactions, neuroleptic malignant syndrome or paradoxical reactions). This is in keeping with a mixture of single agent studies for the treatment of agitation and aggression in children where they seem to be well tolerated and safe $\mathrm{e}^{14,23,24,25}$. The APA remains concerned about risk-benefit trade-off of the use of antipsychotic agents in children outside of FDA-approved indications ${ }^{18}$. It is pertinent when administering such medications to children that a stepwise approach to treatment is used and appropriate post sedation monitoring is commenced in an appropriately staffed area of the ED.

The consensus based clinical practice guideline (CPG) at $\mathrm{RCH}$ advises weight specific doses of oral olanzapine, lorazepam, quetiapine, diazepam or risperidone if the patient accepts oral sedation ${ }^{29}$. The CPG does not recommend which drug may be most suitable or effective, simply that they may be used for all causes of agitation including recreational drug ingestion. For parenteral treatment the guideline advises IM droperidol or olanzapine. Third line agents include IM/IV ketamine or midazolam if the patient has not settled after two doses of other IM medications. The range of

This article is protected by copyright. All rights reserved. 
medications used to treat our patient cohort was consistent with the broad CPG recommendations. No drug was used outside of this guideline.

The 2015 NICE Guideline on short-term management of violence and aggression advises the use of IM lorazepam for rapid tranquilisation of a child or young person and to adjust the dose according to their age and weight ${ }^{9}$. The NICE Guideline on the management of children with conduct disorders and antisocial behaviour advises not to offer pharmacological interventions for the routine management of their behavioural problems ${ }^{30}$. It encourages, in severe cases, to consider giving risperidone. On examining the references from these NICE guidelines they express caution with prescription as, at the time of publication, the advised medications did not have authorisation for use in children and youths with the specific $\mathrm{MH}$ diagnoses.

\section{Limitations}

This was a retrospective study from a single institution. We tried to mitigate the retrospective limitations by the use of a detailed protocol and data dictionary and trained abstractors with intermittent audits of work ${ }^{28}$.

Only medications administered within the ED were examined in this study. We were unable to record any pre-hospital medications administered due to the inconsistent uploading of paramedic data. The order and timing of medication given within the ED was recorded accurately on the EMR. However, neither the EMR nor the chart

This article is protected by copyright. All rights reserved. 
review could be used to reliably determine if the medication was administered for acute de-escalation, tranquilisation, and sedation or per scheduled routine. As previously documented in the literature ${ }^{31}$, a further issue encountered with the electronic data quality was that the codes available to clinicians were often vague, inappropriate and inaccurate. This prompted us to manually check the notes of all included patients for accurate diagnostic data.

\section{CONCLUSION}

Few children with $\mathrm{MH}$ disease were medicated in ED but of those that were, a variety of medications and routes were used. Most frequent diagnoses associated with medication use were ABD and SI. Considering the variation in use of psychotropic medications and the paucity of high-level evidence in children and adolescents, further research is needed in acute psychotropic agents for oral and parenteral use in the emergency setting.

This article is protected by copyright. All rights reserved. 


\section{REFERENCES}

1. Tran QN, Lambeth LG, Sanderson K, et al. Trends of emergency department presentations with a mental health diagnosis by age, Australia, 2004-05 to 2016-17: A secondary data analysis. Emerg Med Australas. 2019;31(6):10641072.

2. Hiscock H, Neely RJ, Lei S, et al. Paediatric mental health presentations to emergency departments, Victoria, 2008-15. Med J Aust. 2018; 208: 343-348.

3. Perera J, Wand T, Bein KJ, et al. Presentations to NSW emergency departments with self-harm, suicidal ideation, or intentional poisoning, 20102014. Med J Aust. 2018;208(8):348-353.

4. Stewart C, Spicer M, Babl FE. Caring for adolescents with mental health problems: challenges in the emergency department. J Paediatr Child Health. Nov 2006;42(11):726-730.

5. Hoffman JA, Stack AM, Monuteaux MC, et al. Factors associated with boarding and length of stay for pediatric mental health emergency visits. Am J Emerg Med. 2018; Available from URL: http://doi.org/10.1016/j.ajem.2018.12.041

6. Pittsenbarger ZE, Mannix R. Trends in pediatric visits to the emergency department for psychiatric illnesses. Acad Emerg Med. 2013;21:25-31.

7. American College of Emergency Physicians. Pediatric Mental Health

This article is protected by copyright. All rights reserved. 
Emergencies in the Emergency Department. Ann Emerg Med. 2019;73:e33e36

8. Gerson R, Malas N, Mroczkowski MM. Crisis in the Emergency Department: The Evaluation and Management of Acute Agitation in Children and Adolescents. Child Adolesc Psychiatr Clin N Am. 2018 Jul;27(3):367-386.

9. National Institute for Health and Care Excellence. Violence and aggression: short-term management in mental health, health and community settings. National Institute for Health and Care Excellence guidelines, 2015. [Updated May 2015; cited 17 Oct 2019]. Available from URL:

https://www.nice.org.uk/guidance/ng10

10. Knott J, Gerdtz M, Dobson S, et al. Restrictive Interventions in Victorian Emergency Departments: A Review of Current Clinical Practice. Victoria State Government. 2019. Available from URL:

https://www2.health.vic.gov.au/about/publications/researchandreports/rest rictive-interventions-emergency-departments-review

11. Taylor DM, Yap CYL, Knott JC, et al. Midazolam-Droperidol, Droperidol, or Olanzapine for Acute Agitation: A Randomized Clinical Trial. Ann Emerg Med. 2017; 69: 318-326.e1

12. Hopper SM, Franz EB, Steward CE, et al. Aggression management in a children's hospital setting. Med J Austr. 2012;196(3):198-201.

13. Woolfenden S, Dossetor D, Nunn K, et al. The presentation of aggressive

This article is protected by copyright. All rights reserved. 
children and adolescents to emergency departments in Western Sydney. J Paediatr Child Health. 2003;39(9):651-653.

14. Khan SS, Mican LM. A naturalistic evaluation of intramuscular ziprasidone versus intramuscular olanzapine for the management of acute agitation and aggression in children and adolescents. J Child Adolesc Psychopharmacol. 2006;16(6):671-677.

15. Barzman DH, DelBello MP, Forrester JJ, et al. A retrospective chart review of intramuscular ziprasidone for agitation in children and adolescents on psychiatric units: Prospective studies are needed. J Child Adolesc Psychopharmacol. 2007;17(4):503-509.

16. Jangro WC, Preval $\mathrm{H}$, Southard R, et al. Conventional intramuscular sedatives versus ziprasidone for severe agitation in adolescents: case-control study. Child Adolesc Psychiatry Ment Health. 2009;3:9.

17. Dorfman DH, Mehta SD. Restraint use for psychiatric patients in the pediatric emergency department. Pediatr Emerg Care. 2006;22(1):7-12.

18. American Psychiatric Association. Choosing wisely. 2013. Available from URL: http://www.choosingwisely .org/ doctor-patient-lists/american-psychiatricassociation.

19. Gerson R, Malas N, Feuer V et al. Best Practices for Evaluation and Treatment of Agitated Children and Adolescents (BETA) in the Emergency Department: Consensus Statement of the American Association for Emergency Psychiatry.

This article is protected by copyright. All rights reserved. 
West J Emerg Med. 2019 May;20(3):537

20. Steinhausen HC. Recent international trends in psychotropic medication prescriptions for children and adolescents. Eur Child Adolesc Psychiatry. 2015 Jun;24(6):635-40.

21. Baker M, Carlson GA. What do we really know about PRN use in agitated children with mental health conditions: a clinical review. Evid Based Ment Health. 2018 Nov;21(4):166-170. doi: 10.1136/ebmental-2018-300039. Epub 2018 Oct 25.

22. Vitiello B, Hill JL, Elia J, et al. P.r.n. medications in child psychiatric patients: a pilot placebo-controlled study. J Clin Psychiatry 1991;52:499-501.

23. Kendrick JG, Goldman RD, Carr RR. Pharmacologic Management of Agitation and Aggression in a Pediatric Emergency Department - A Retrospective Cohort Study. J Pediatr Pharmacol Ther 2018 Vol. 23 No. 6

24. Page CB, Parker LE, Rashford SJ, et al. A Prospective Study of the Safety and Effectiveness of Droperidol in Children for Prehospital Acute Behavioral Disturbance. Prehospital Emergency Care, DOI:10.1080/10903127.2018.1542473

25. Szwak K, Sacchetti A. Droperidol Use in Pediatric Emergency Department Patients. Pediatric Emergency Care \& Volume 26, Number 4, April 2010.

26. Victoria State Government. Mental Health Act, Stat. 14-026. Victorian Legislation and Parliamentary Documents. 2014; [Cited 17 Oct 2019].

This article is protected by copyright. All rights reserved. 
Available from URL: http://legislation.vic.gov.au

27. Australasian College for Emergency Medicine. Guidelines on the implementation of the Australasian Triage Scale in emergency departments. [Uptdated Jul 2016; cited 04 Aug 2020]. Available from URL: https://acem.org.au/getmedia/51dc74f7-9ff0-42ce-872a0437f3db640a/G24 04 Guidelines on Implementation of ATS Jul16.aspx

28. Kaji A, Schriger D, Green S. Looking Through the Retrospectoscope: Reducing Bias in Emergency Medicine Chart Review Studies. Ann Emerg Med. 2014; 64: 292-298.

29. The Royal Children's Hospital, Melbourne. Acute behavioural disturbance: Acute management. Clinical Practice Guidelines. [Updated Jul 2017; cited 17 Mar 2020]. Available from URL: https://www.rch.org.au/clinicalguide/guideline_index/acute_behavioural_dis turbance_acute_management/

30. National Institute for Health and Care Excellence. Antisocial behaviour and conduct disorders in children and young people: recognition and management. Clinical guideline [CG158]Published date: March 2013. Last updated: April 2017. Available from URL: https://www.nice.org.uk/guidance/cg158

31. Spillane IM, Krieser D, Dalton S, et al. Limitations to diagnostic coding

This article is protected by copyright. All rights reserved. 
accuracy in emergency departments: implications for research and audits of care. Emerg Med Australas. 2010 Feb;22(1):91-2.

This article is protected by copyright. All rights reserved. 
TABLES

Table 1: Comparison of demographics and ED variables of total mental health presentations and medicated versus non-medicated subsets

\begin{tabular}{|c|c|c|c|c|}
\hline Demographics & $\begin{array}{c}\text { Total } \mathrm{MH}+ \\
\text { presentations } \\
\mathrm{n}=1695 \\
\end{array}$ & $\begin{array}{l}\text { Medicated } \\
n=\mathbf{2 8 0}\end{array}$ & $\begin{array}{c}\text { Non- } \\
\text { Medicated } \\
n=1415 \\
\end{array}$ & Comparison \\
\hline Sex & $\mathrm{n}(\%)$ & n (\%) & $\mathrm{n}(\%)$ & OR $(95 \% \mathrm{Cl}) \neq$ \\
\hline Female & $1132(66.8)$ & 165 (58.9) & $967(68.3)$ & Male: Female \\
\hline Male & $563(33.2)$ & $115(41.1)$ & $448(31.7)$ & $1.50(1.16-1.96)$ \\
\hline \multicolumn{5}{|l|}{ Age (years) } \\
\hline $7-10$ & $182(10.7)$ & 37 (13.2) & 145 (10.2) & \multirow{3}{*}{$\begin{array}{c}\geq 14 \text { years: }<14 \text { years } \\
0.94(0.72-1.23)\end{array}$} \\
\hline $11-14$ & $675(39.8)$ & $96(34.3)$ & 579 (40.9) & \\
\hline $15-17$ & $838(49.4)$ & $147(52.5)$ & $691(48.8)$ & \\
\hline \multicolumn{5}{|l|}{ Triage category } \\
\hline 1 & $24(1.4)$ & $12(4.3)$ & $12(0.9)$ & \multirow{5}{*}{$\begin{array}{c}\text { Category 1-2: } \\
\text { Category } 3-5 \\
3.37(2.28-4.98)\end{array}$} \\
\hline 2 & 100 (5.9) & 34 (12.1) & $66(4.7)$ & \\
\hline 3 & $1120(66.1)$ & $194(69.3)$ & $926(65.4)$ & \\
\hline 4 & $423(25.0)$ & $38(13.6)$ & 385 (27.2) & \\
\hline 5 & $28(1.7)$ & $2(0.7)$ & $26(1.8)$ & \\
\hline \multicolumn{5}{|l|}{ Length of stay } \\
\hline$<4 \mathrm{hrs}$ & 706 (41.7) & 93 (33.2) & $613(43.3)$ & \multirow{4}{*}{$\begin{array}{c}\geq 12 \text { hours: }<12 \text { hours } \\
3.96(2.56-6.13)\end{array}$} \\
\hline$\geq 4-<8 \mathrm{hrs}$ & 792 (46.7) & $120(42.9)$ & $672(47.5)$ & \\
\hline$\geq 8-<12 \mathrm{hrs}$ & $105(6.2)$ & $29(10.4)$ & $76(5.4)$ & \\
\hline$\geq 12 \mathrm{hrs}$ & $92(5.4)$ & $38(13.6)$ & $54(3.8)$ & \\
\hline \multicolumn{5}{|l|}{ Arrival day } \\
\hline Weekday & $1314(77.5)$ & $213(76.1)$ & $1101(77.8)$ & \multirow{2}{*}{$\begin{array}{c}\text { Weekend: Weekday } \\
1.10(0.82-1.49)\end{array}$} \\
\hline Weekend & $381(22.5)$ & 67 (23.9) & $314(22.2)$ & \\
\hline \multicolumn{5}{|l|}{ Arrival time } \\
\hline 0000-0759 & $160(9.4)$ & $33(11.8)$ & $127(9.0)$ & \multirow{5}{*}{$\begin{array}{c}\text { After hours: In hours } \\
1.51(1.16-1.96)\end{array}$} \\
\hline 0800-1559 & $647(38.2)$ & 87 (31.1) & $560(39.6)$ & \\
\hline $1600-2359$ & $888(52.4)$ & $160(57.1)$ & $728(51.4)$ & \\
\hline After hours (1700-0759) & 931 (54.9) & $177(63.2)$ & $754(53.3)$ & \\
\hline In hours (0800-1659) & $764(45.1)$ & $103(36.8)$ & $661(46.7)$ & \\
\hline
\end{tabular}

$+\mathrm{MH}$ : Mental health

₹ Odd Ratios (OR) and 95\% confidence intervals (Cl) calculating the likelihood of presentation variables in medicated cohort, compared to non-medicated cohort.

This article is protected by copyright. All rights reserved. 
Table 2. Comparison of presentation variables of medicated subset of mental health presentations versus non-medicated subset

\begin{tabular}{|c|c|c|c|}
\hline Presentation variable & $\begin{array}{c}\text { Medicated } \\
n=\mathbf{2 8 0}\end{array}$ & $\begin{array}{c}\text { Non- } \\
\text { Medicated } \\
\mathrm{n}=1415 \\
\end{array}$ & Comparison \\
\hline Means of arrival & $n(\%)$ & n (\%) & OR $(95 \% \mathrm{Cl}) \dagger$ \\
\hline Private car / self / public transport & $133(47.5)$ & 904 (63.9) & \multirow{4}{*}{$\begin{array}{l}\text { Police/Ambulance: } \\
\text { Private/other transport } \\
1.97(1.52-2.56)\end{array}$} \\
\hline Police & $76(27.1)$ & $216(15.3)$ & \\
\hline Ambulance & $71(25.4)$ & $292(20.6)$ & \\
\hline Unknown & 0 & $3(0.2)$ & \\
\hline \multicolumn{4}{|l|}{ Sectioned } \\
\hline No & $219(78.2)$ & $1241(87.7)$ & \multirow{3}{*}{$\begin{array}{l}\text { Sectioned: Not } \\
1.93(1.39-2.68)\end{array}$} \\
\hline Yes & $59(21.1)$ & $171(12.2)$ & \\
\hline Unknown & $2(0.7)$ & $2(0.1)$ & \\
\hline \multicolumn{4}{|l|}{ Guardianship } \\
\hline Parent & $229(81.8)$ & $1246(88.1)$ & \multirow{5}{*}{$\begin{array}{c}\text { DHHS/Police: } \\
\text { Parent/other } \\
1.87(1.28-2.73)\end{array}$} \\
\hline DHHS $\neq$ & $42(15.0)$ & $118(8.3)$ & \\
\hline Other family & $6(2.1)$ & $39(2.8)$ & \\
\hline Unknown & $3(1.1)$ & $8(0.6)$ & \\
\hline Police custody & 0 & $4(0.3)$ & \\
\hline \multicolumn{4}{|l|}{ Attended with } \\
\hline Parent & $203(72.5)$ & $1132(80.0)$ & \multirow{8}{*}{$\begin{array}{l}\text { DHHS/social worker: } \\
\text { Parent/other } \\
2.64(1.77-3.94)\end{array}$} \\
\hline DHHS $\ddagger /$ residential care/social worker & $40(14.3)$ & $84(5.9)$ & \\
\hline Alone & $22(7.9)$ & $85(6.0)$ & \\
\hline Other family & $10(3.6)$ & $61(4.3)$ & \\
\hline Unknown & $3(1.1)$ & $19(1.3)$ & \\
\hline Community psychiatric liaison & $1(0.4)$ & 0 & \\
\hline Friend & $1(0.4)$ & $26(1.8)$ & \\
\hline Teacher & 0 & $8(0.6)$ & \\
\hline \multicolumn{4}{|l|}{ Prior psychiatric / community care } \\
\hline Yes & $240(85.7)$ & $1092(77.2)$ & \multirow{3}{*}{$\begin{array}{c}\text { Prior psychiatric care: } \\
\text { None/unknown } \\
1.77(1.24-2.54)\end{array}$} \\
\hline No & 39 (13.9) & $311(22.0)$ & \\
\hline Unknown & $1(0.4)$ & $12(0.8)$ & \\
\hline \multicolumn{4}{|l|}{ Past psychiatric diagnosis } \\
\hline Yes & $254(90.7)$ & $1004(71.0)$ & \multirow{3}{*}{$\begin{array}{l}\text { Past diagnosis: } \\
\text { None/unknown } \\
4.0(2.63-6.08)\end{array}$} \\
\hline No & $26(9.3)$ & $386(27.3)$ & \\
\hline Unknown & 0 & $25(1.8)$ & \\
\hline \multicolumn{4}{|l|}{ Disposition from Emergency Department } \\
\hline Home & $186(66.4)$ & $948(67.0)$ & \multirow{6}{*}{$\begin{array}{l}\text { Admitted: Discharged } \\
1.16(0.87-1.55)\end{array}$} \\
\hline Admitted to Royal Children's Hospital & $51(18.2)$ & $279(19.7)$ & \\
\hline Admitted to another facility & $24(8.6)$ & $60(4.2)$ & \\
\hline Residential care & $14(5.0)$ & $60(4.2)$ & \\
\hline DHHS $\ddagger$ & $3(1.1)$ & $26(1.8)$ & \\
\hline Relative & $1(0.4)$ & $18(1.3)$ & \\
\hline
\end{tabular}

This article is protected by copyright. All rights reserved. 


\begin{tabular}{lccc} 
Absconded & $1(0.4)$ & $14(1.0)$ & \\
Police custody & 0 & $10(0.7)$ & \\
Total discharged (any location) & $205(73.2)$ & $1076(76.0)$ & \\
Total admitted (any location) & $75(26.8)$ & $339(24.0)$ & \\
Discharged with & & & \\
Parent & $208(74.3)$ & $1160(82.0)$ & \\
DHHS $\ddagger$ /residential care/social worker & $46(16.4)$ & $117(8.3)$ & DHHS/police: \\
Other & $15(5.4)$ & $57(4.0)$ & Parent/other \\
Unknown & $6(2.1)$ & $21(1.5)$ & $2.11(1.48-3.02)$ \\
Police & $3(1.1)$ & $12(0.8)$ & \\
Alone & $1(0.4)$ & $22(1.6)$ & \\
Friend & $1(0.4)$ & $26(1.8)$ & \\
Follow up arrangements & & & \\
Community psychiatric services & $187(66.8)$ & $872(61.6)$ & N/A \\
Private psychiatrist / counsellor & $23(8.2)$ & $165(11.7)$ & \\
Outpatient psychiatry & $21(7.5)$ & $49(3.5)$ & \\
Transfer to another unit & $19(6.8)$ & $46(3.3)$ & \\
Paediatrician & $16(5.7)$ & $103(7.3)$ & \\
Unknown & $7(2.5)$ & $27(1.9)$ & \\
General Practitioner & $2(0.7)$ & $91(6.4)$ & \\
None & $4(1.4)$ & $38(2.7)$ & \\
Return to Emergency Department & $1(0.4)$ & $24(1.7)$ & \\
\hline
\end{tabular}

† Odd Ratios (OR) and 95\% confidence intervals (Cl) calculating the likelihood of presentation variables in medicated cohort, compared to non-medicated cohort. $\neq$ DHHS: Department of Health and Human Services

This article is protected by copyright. All rights reserved. 
Table 3. Major diagnostic groups ${ }^{\dagger}$ and medications received

\begin{tabular}{|c|c|c|c|c|}
\hline & $\begin{array}{l}\text { All presentations } \\
\text { receiving } \\
\text { medications } \\
n=280\end{array}$ & $\begin{array}{c}\text { Acute behavioural } \\
\text { disturbance } \\
n=96\end{array}$ & $\begin{array}{l}\text { Suicidal ideation } \\
\qquad n=94\end{array}$ & $\begin{array}{c}\text { Other diagnoses }{ }^{\dagger} \\
n=90\end{array}$ \\
\hline & n (\%) & n (\%) & n (\%) & n (\%) \\
\hline Total number of presentations & 280 & 96 & 94 & 90 \\
\hline \multicolumn{5}{|l|}{ Medication Route } \\
\hline Oral only & $256(91.4)$ & $80(83.3)$ & $90(95.7)$ & $86(95.6)$ \\
\hline Intramuscular (at least once) & $24(8.6)$ & $16(16.7)$ & $4(4.3)$ & $4(4.4)$ \\
\hline \multicolumn{5}{|c|}{ Number of medication administrations } \\
\hline 1 & $213(76.1)$ & $68(70.8)$ & $76(80.9)$ & $69(76.7)$ \\
\hline 2 & $40(14.3)$ & $12(12.5)$ & $16(17.0)$ & $12(13.3)$ \\
\hline 3 & $15(5.4)$ & $8(8.3)$ & $2(2.1)$ & $5(5.6)$ \\
\hline$\geq 4$ & $12(4.3)$ & $8(8.3)$ & 0 & $4(4.4)$ \\
\hline \multicolumn{5}{|c|}{ Most commonly prescribed intramuscular (IM) medications } \\
\hline Total IM $\ddagger$ administrations & 40 & 23 & 5 & 12 \\
\hline Droperidol IM 5mg & $13(32.5)$ & $9(39.1)$ & $4(80.0)$ & 0 \\
\hline Olanzapine IM 10mg & $9(22.5)$ & $6(26.1)$ & 0 & $3(25.0)$ \\
\hline \multicolumn{5}{|c|}{ Most commonly prescribed oral (PO) medications } \\
\hline Total PO§ administrations & 348 & 135 & 109 & 104 \\
\hline Diazepam PO $5 \mathrm{mg}$ & $102(29.3)$ & $17(12.6)$ & $50(45.9)$ & $35(33.7)$ \\
\hline Olanzapine PO 5mg & $75(21.6)$ & $32(23.7)$ & $22(20.2)$ & $21(20.2)$ \\
\hline Lorazepam PO $1 \mathrm{mg}$ & $37(10.6)$ & $18(13.3)$ & $10(9.2)$ & $9(8.7)$ \\
\hline
\end{tabular}


† Diagnostic groups based on Emergency Doctor diagnosis outlined in Table 5.

¥ IM: Intramuscular

$\S$ PO: Per oral route includes all orally ingested and sublingual routes 
Table 4. Total medication administrations $(n=388)$

\begin{tabular}{lccccc}
\hline \multicolumn{1}{|c}{ Medication } & $\begin{array}{c}\text { Medication } \\
\text { given anytime } \\
\text { during visit } \\
\mathbf{n}(\%)\end{array}$ & $\begin{array}{c}\text { Medication } \\
\text { given first } \\
\text { line } \\
\mathbf{n}(\%)\end{array}$ & $\begin{array}{c}\text { Medication } \\
\text { given second } \\
\text { line } \\
\mathbf{n}(\%)\end{array}$ & $\begin{array}{c}\text { Medication } \\
\text { given third } \\
\text { line } \\
\mathbf{n}(\%)\end{array}$ & $\begin{array}{c}\text { Median } \\
\text { Total Dose } \\
\text { mg (range) }\end{array}$ \\
\hline $\begin{array}{l}\text { Total drug } \\
\text { administrations } \\
\mathrm{n} \text { (\% total) }+\end{array}$ & $388(100)$ & $280(72.2)$ & $64(16.5)$ & $23(5.9)$ & \\
\hline $\begin{array}{l}\text { Diazepam } \\
\text { Droperidol }\end{array}$ & $168(43.3)$ & $144(51.4)$ & $18(28.1)$ & $4(17.4)$ & $5(1-20)$ \\
\hline Lorazepam & $15(3.9)$ & $6(2.1)$ & $3(4.7)$ & $3(13.0)$ & $5(0.5-10)$ \\
\hline Midazolam & $12(3.1)$ & $2(0.7)$ & $6(9.4)$ & $2(8.7)$ & $5(2-10)$ \\
\hline Olanzapine & $100(25.8)$ & $71(25.4)$ & $18(28.1)$ & $5(21.7)$ & $5(2.5-10)$ \\
\hline Risperidone & $34(8.8)$ & $17(6.1)$ & $8(12.5)$ & $4(17.4)$ & $1(0.3-4)$ \\
\hline
\end{tabular}

+ Percentage of total 388 individual drug administrations (via any route) given anytime during visit

This article is protected by copyright. All rights reserved. 
Table 5. Diagnoses in medicated cohort $(n=280)$

\begin{tabular}{lcc}
\hline \multicolumn{1}{c}{ Diagnosis } & $\begin{array}{c}\text { Emergency Doctor } \\
\text { Diagnosis } \\
\mathbf{n}(\%)\end{array}$ & $\begin{array}{c}\text { Mental Health } \\
\text { Practitioner Diagnosis } \\
\mathbf{n}(\%)\end{array}$ \\
\hline Acute behavioural disturbance & $96(34.3)$ & $81(28.9)$ \\
\hline Acute psychosis & $12(4.3)$ & $14(5.0)$ \\
\hline Affective bipolar disorder & $1(0.4)$ & $1(0.4)$ \\
\hline Anorexia nervosa or Eating Disorder & $1(0.4)$ & $1(0.4)$ \\
Anxiety & $28(10.0)$ & $17(6.1)$ \\
Anxiety and depression & 0 & $5(1.8)$ \\
Depression & $4(1.4)$ & $4(1.4)$ \\
Drug induced psychosis & $2(0.7)$ & $2(0.7)$ \\
Drug overdose & $14(5.0)$ & $7(2.5)$ \\
Drug withdrawal & $1(0.4)$ & $1(0.4)$ \\
Emotional dysregulation & $3(1.1)$ & $8(2.9)$ \\
Hallucinations & $7(2.5)$ & $6(2.1)$ \\
No recorded diagnosis ${ }^{\dagger}$ & 0 & $23(8.2)$ \\
Self-harm & $13(4.6)$ & $15(5.4)$ \\
Somatoform disorder & $1(0.4)$ & $2(0.7)$ \\
Suicidal and homicidal ideation & $1(0.4)$ & $2(0.7)$ \\
Suicidal ideation & $94(33.6)$ & $87(31.1)$ \\
Suicide attempt & $2(0.7)$ & $3(1.1)$ \\
\hline Tourette's syndrome & 0 & $1(0.4)$ \\
\hline
\end{tabular}

† All patients had an Emergency Doctor diagnosis recorded. 23 patients were not seen by a Mental Health Practitioner and hence did not have a Mental Health Practitioner diagnosis recorded.

This article is protected by copyright. All rights reserved. 
Supplemental Table 1. Total medication administrations $(n=388)$

\begin{tabular}{lccc}
\hline Medication & $\begin{array}{c}\text { Medication given } \\
\text { anytime during visit } \\
\mathbf{n}(\%)\end{array}$ & $\begin{array}{c}\text { Doses via } \\
\text { intramuscular route } \\
\mathbf{n}(\%)\end{array}$ & $\begin{array}{c}\text { Median Total Dose } \\
\mathbf{m g} \text { (range) }\end{array}$ \\
\hline Diazepam & $168(43.3)$ & $1(0.6)$ & $5(1-20)$ \\
Droperidol & $15(3.9)$ & $15(100)$ & $5(0.5-10)$ \\
Lorazepam & $59(15.2)$ & 0 & $1(0.5-2)$ \\
Midazolam & $12(3.1)$ & $9(75)$ & $5(2-10)$ \\
Olanzapine & $100(25.8)$ & $15(15)$ & $5(2.5-10)$ \\
Risperidone & $34(8.8)$ & 0 & $1(0.3-4)$ \\
\hline
\end{tabular}

This article is protected by copyright. All rights reserved. 
Appendix 1: List of 66 International Classification of Diseases, Revision 10, Australian Modification (ICD-10-AM) Diagnostic Codes used for patient inclusion. ICD-10-AM Mental Health Diagnostic Codes for patient inclusion

Accidental drug overdose

Accidental paracetamol overdose

Acute anxiety

Acute depression

Acute drug overdose

Acute post-traumatic stress disorder

Acute stress disorder

Affective bipolar disorder

Anorexia

Anorexia nervosa

Anxiety disorder

Behaviour disorder

Behavioural disorder

Borderline personality disorder

Chronic depression

Depression with suicidal ideation

Destructive behaviour

Drug addiction

Drug dependence

Drug ingestion

Drug overdose, multiple drugs

Drug withdrawal

Drug-induced mental disorder

Emotional crisis

Emotional disorder

Emotionally unstable borderline personality disorder

Hallucination

History of self-harm

Hysteria

Intentional drug overdose

Intentional paracetamol overdose

Manic depression

Manic disorder

Mental and behavioural disorders due to use of alcohol, acute

intoxication

Mental disorder

Mental health disorder

Multiple drug overdose

Non-accidental drug overdose

Overdose of medication

Overdose of psychotropic

Overdose of sedative or hypnotic

This article is protected by copyright. All rights reserved. 


\begin{tabular}{|l|}
\hline Overdose of tricyclic \\
Paracetamol overdose \\
Paracetamol overdose of undetermined intent \\
Persistent mood disorder \\
Post-traumatic stress disorder \\
Psychiatric disorder \\
Psychosomatic disease \\
Psychosomatic disorder \\
Reactive psychosis \\
Schizophrenia \\
Social problem \\
Somatoform disorder \\
Stress and adjustment reaction \\
Suicidal ideation \\
Suicidal risk \\
Suicidal thoughts \\
Suicide by hanging \\
Suicide ideation \\
\hline Additional ICD-10-AM Diagnostic Codes for patient inclusion \\
\hline Laceration of upper arm \\
Laceration of wrist \\
Forearm laceration \\
Wrist laceration \\
Ingestion of foreign body \\
Swallowed foreign body \\
\hline
\end{tabular}

This article is protected by copyright. All rights reserved. 


\section{University Library}

\section{- M M N E R VA A gateway to Melbourne's research publications}

Minerva Access is the Institutional Repository of The University of Melbourne

Author/s:

O'Donnell, SM;Carison, A;Hill, A;Say, D;Hiscock, H;Babl, FE

Title:

Psychotropic medication use for paediatric mental health patients in an emergency department

Date:

2020-09-30

Citation:

O'Donnell, S. M., Carison, A., Hill, A., Say, D., Hiscock, H. \& Babl, F. E. (2020).

Psychotropic medication use for paediatric mental health patients in an emergency department. EMERGENCY MEDICINE AUSTRALASIA, 33 (2), pp.292-301. https:// doi.org/10.1111/1742-6723.13617.

Persistent Link:

http://hdl.handle.net/11343/276373 